\title{
Modelagem matemática da matéria orgânica do solo em sistema silvipastoril biofertilizado com água residuária da suinocultura
}

\section{Giulia Faria Shimamoto1,*, Beno Wendling ${ }^{1}$ e Fabrício Pelizer de Almeida ${ }^{2}$}

${ }^{1}$ Universidade Federal de Uberlândia. Programa de Pós-Graduação em Qualidade Ambiental. Campus Glória. Rodovia BR-050, km 78, S/№. Uberlândia-MG, Brasil (CEP 38410-337).*E-mail: giula.shimamoto@gmail.com.

${ }^{2}$ Universidade de Uberaba. Instituto de Tecnologia. Avenida Afonso Pena, 1177. Campus Marileusa. Granja Marileusa. Uberlândia-MG, Brasil (CEP 38400-706).

Resumo. 0 interesse em compreender a dinâmica da matéria orgânica do solo (MOS) consiste na sua relevância para a funcionalidade e qualidade dos ecossistemas. Sob essa perspectiva, o presente trabalho objetiva analisar a MOS em função das características físicas e químicas do solo e definir o cenário de sua máxima expressão. A pesquisa foi conduzida em áreas de pastagem solteira e de sistemas silvipastoris em linhas simples e dupla, localizadas no município de Uberlândia, Minas Gerais, Brasil. Foram analisadas as doses 0, 200, 400, 600 e 800 $\mathrm{m}^{3} \cdot \mathrm{ha}^{-1}$ de água residuária da suinocultura (ARS) tratada nas profundidades 0,0-0,2 m e 0,2-0,4 $\mathrm{m}$. Os aninhamentos entre os fatores área, profundidade e tratamento indicaram que os nutrientes magnésio e manganês, bem como o sistema silvipastoril em linha simples e a dose $600 \mathrm{~m}^{3} \cdot \mathrm{ha}^{-1}$ destacaram-se significativos e diretamente proporcionais à dinâmica da MOS. A metodologia de otimização de resposta evidenciou que o cenário de máxima expressão da MOS resulta da interação do sistema silvipastoril em linha simples, na camada 0,0-0,2 m, com a dose $600 \mathrm{~m}^{3} \cdot \mathrm{ha}^{-1}$, o que valida os resultados obtidos nos modelos lineares generalizados.

Palavras-chave: Modelo linear generalizado; Aninhamento; Maximização de resposta.

Abstract. Mathematical modeling of soil organic matter in biofertilized silvopastoral system with swine wastewater. The concern in understanding the dynamics of soil organic matter (SOM) consists of its relevance to the function and quality of ecosystems. From this perspective, this paper aims to analyze the SOM according to the physical-chemical characteristics of the soil and define the scenario of its maximum expression. The research was conducted in areas of single pasture and silvopastoral systems, in single and double lines, located in Uberlandia city, Minas Gerais, Brazil. The doses 0, 200, 400, 600 and $800 \mathrm{~m}^{3}$.ha ${ }^{-1}$

Recebido $18 / 03 / 2021$

Aceito $25 / 04 / 2021$

Publicado $30 / 04 / 2021$

Acesso aberto

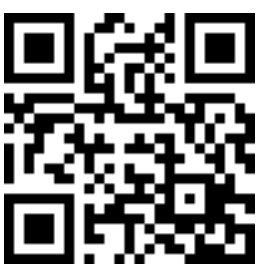

ORCID

D) 0000-0002-9832-8105

Giulia Faria

Shimamoto

D $0000-0002-8812-1661$ Beno Wendling

(D) 0000-0002-0995-8536

Fabrício Pelizer de Almeida

ISSN 2359-1412/RBGAS-2021-0029/2021/8/18/33/513

Rev. Bras. Gest. Amb. Sustent.

http://revista.ecogestaobrasil.net 
of treated swine wastewater were analyzed at depths $0.0-0.2 \mathrm{~m}$ and 0.2-0.4 $\mathrm{m}$. The nestings between area, depth, and treatment indicated that the rates of magnesium and manganese; silvopastoral system in a single line and the dose $600 \mathrm{~m}^{3} \cdot \mathrm{ha}^{-1}$ have stood out significant and directly proportional to the dynamics of SOM. The maximum expression of SOM was found in the $0.0-0.2 \mathrm{~m}$ layer, dose $600 \mathrm{~m}^{3} \cdot \mathrm{ha}^{-1}$ at the single line silvopastoral system, according to the response optimization methodology, which validates the results obtained in the generalized linear models.

Keywords: Generalized linear model; Nestedness; Response maximization.

\section{Introdução}

A suinocultura é uma atividade de referência no agronegócio brasileiro. Segundo o Relatório Anual da Associação Brasileira de Proteína Animal (ABPA, 2020), em 2019, a produção de carne suína alcançou 3,983 milhões de toneladas, sendo $81 \%$ deste total destinados ao mercado interno. Neste mesmo ano, o Brasil manteve a quarta posição no ranking mundial de maior produtor e exportador deste produto, arrecadando receita de 1.597 milhões de dólares (ABPA, 2020).

0 passivo ambiental desta atividade é decorrente da destinação final inadequada do seu efluente, denominado água residuária da suinocultura (ARS), tanto pelo elevado volume gerado quanto pela sua caracterização química (Smanhotto et al., 2010). Estudos que comprovem o potencial biofertilizante da ARS são interessantes para reduzir os efeitos decorrentes do seu descarte incorreto, que contraria a legislação ambiental e impacta negativamente o sistema solo-planta-recursos hídricos.

0 aproveitamento da ARS tratada em sistemas produtivos é uma alternativa para desenvolver práticas de manejo conservacionistas e fortalecer os princípios da sustentabilidade na atividade produtiva. Dentre os benefícios da fertirrigação com ARS cita-se o acúmulo de matéria orgânica no solo, que condiciona melhoria das condições físico-químicas e biológicas do solo; e, portanto, é um parâmetro relevante para a funcionalidade e qualidade dos ecossistemas (Vilela e Mendonça, 2013).

$\mathrm{Na}$ intenção de compreender melhor o comportamento de variáveis ambientais, a modelagem matemática vem sendo aplicada em pesquisas voltadas ao estudo de sistemas naturais. 0 modelo linear generalizado (Generalized Linear Model - GLM) é um modelo de regressão, que objetiva estudar a influência que uma ou mais variáveis exercem sobre uma ou mais variáveis de interesse (Cordeiro e Demétrio, 2013; McCullagh e Nelder, 2019). A metodologia de otimização de resposta permite identificar a melhor combinação das variáveis explicativas para determinar a ótima expressão da variável resposta; associada ao modelo GLM, direciona melhor compreensão da dinâmica das variáveis analisadas sobre um determinado fenômeno. Tal associação constitui, portanto, ferramenta relevante para subsidiar a adoção de medidas que favoreçam o acúmulo e a manutenção da MOS.

Desse modo, a presente pesquisa propõe avaliar a ótima capacidade de resposta da matéria orgânica do solo (MOS) em um sistema silvipastoril biofertilizado com água residuária da suinocultura, por meio de GLMs e da técnica de otimização de resposta. 


\section{Materiais e métodos}

Os estudos foram desenvolvidos na Fazenda Bonsucesso, localizada no Município de Uberlândia, no Estado de Minas Gerais, em área de cerrado já estabelecido. 0 solo é classificado como Latossolo Vermelho Amarelo Distrófico Típico, com horizonte A moderado e de textura arenosa (Santos et al., 2013). Segundo o sistema de classificação de Köppen (Alvares et al., 2013), o clima da região é do tipo Aw, tropical típico, apresentando excesso de chuvas no verão e moderado déficit hídrico no inverno, com média de precipitação de $1.600 \mathrm{~mm}$ por ano.

0 trabalho consistiu na aplicação da água residuária da suinocultura (ARS) tratada nas doses 0, 200, 400, 600 e $800 \mathrm{~m}^{3} \cdot$ ha $^{-1}$ (Tabelas 1 e 2), com aplicações ao longo do ano de 2015, compondo o planejamento de cinco tratamentos e quatro repetições.

0 experimento foi conduzido em três áreas: i) pastagem solteira (PS) com a espécie Urochloa decumbens; ii) sistema silvipastoril em linha simples (LS): linha simples de Corymbia citriodora e pastagem; iii) sistema silvipastoril em linha dupla (LD): linha dupla de Corymbia citriodora e pastagem.

Tabela 1. Teores de macro e micronutrientes da ARS utilizada no experimento.

\begin{tabular}{|c|c|c|c|c|c|c|c|c|c|c|c|c|}
\hline \multirow{2}{*}{ Parâmetro } & MO & $\mathbf{N}$ & $\mathbf{P}$ & $\mathbf{K}$ & $\mathbf{C a}$ & Mg & $\mathrm{Na}$ & B & $\mathrm{Cu}$ & $\mathbf{F e}$ & Mn & $\mathbf{Z n}$ \\
\hline & \multicolumn{6}{|c|}{ - } & \multicolumn{6}{|c|}{ - } \\
\hline Valor & 0,7 & 0,3 & 1,0 & 0,3 & 0,6 & 1,0 & 400,0 & 0,1 & 8,7 & 13,7 & 13,3 & 6,3 \\
\hline
\end{tabular}

MO: Matéria orgânica; N: Nitrogênio; P: Fósforo; K: Potássio; Ca: Cálcio; Mg: Magnésio; Na: Sódio; B: Boro; Cu: Cobre; Fe: Ferro; Mn: Manganês; Zn: Zinco.

Tabela 2. Caracterização química da ARS utilizada no experimento.

\begin{tabular}{|c|c|c|c|c|}
\hline \multirow{2}{*}{ Parâmetro } & \multirow{2}{*}{$\mathbf{p H}$} & DBO & DQO & SST \\
\hline & & \multicolumn{3}{|c|}{ - - - } \\
\hline Valor & 7,62 & 728,45 & $1.956,45$ & 641,67 \\
\hline
\end{tabular}

DBO: Demanda bioquímica de oxigênio; DQO: Demanda química de oxigênio; SST: Sólidos suspensos totais.

Para a avaliação física e química do solo foram coletadas amostras simples nas camadas 0,0-0,20 m (X) e 0,20-0,40 m (Y). Tais amostras foram homogeneizadas para formarem amostras compostas, as quais foram utilizadas na caracterização química (Tabela 3).

Tabela 3. Caracterização química do solo da área experimental.

\begin{tabular}{|c|c|c|c|c|c|c|c|c|c|c|c|c|c|c|c|}
\hline \multirow{2}{*}{$\begin{array}{c}\text { Profundidade } \\
\text { (m) }\end{array}$} & \multirow{2}{*}{ pH } & MOS & SB & $\mathrm{Na}$ & $\mathbf{C a}$ & Mg & $\mathbf{A l}$ & $\mathbf{S}$ & $\mathbf{P}$ & $\mathbf{K}$ & B & $\mathbf{C u}$ & $\mathbf{F e}$ & Mn & $\mathbf{Z n}$ \\
\hline & & \multicolumn{6}{|c|}{ - } & \multicolumn{8}{|c|}{ - } \\
\hline $0,0-0,2$ & 5,7 & 17 & 1,47 & 273 & 0,9 & 0,5 & 0,3 & 15,9 & 9,6 & 29 & 0,11 & 0,8 & 36 & 3,6 & 1,2 \\
\hline $0,2-0,4$ & 5,7 & 7 & 0,94 & 201 & 0,7 & 0,2 & 0,4 & 22,7 & 3,3 & 15 & 0,07 & 0,8 & 23 & 1,8 & 0,5 \\
\hline
\end{tabular}

MOS: Matéria orgânica do solo; SB: Soma de Bases; Na: Sódio; Ca: Cálcio; Mg: Magnésio; Al: Alumínio; S: Enxofre; P: Fósforo; K: Potássio; B: Boro; Cu: Cobre; Fe: Ferro; Mn: Manganês; Zn: Zinco. 
Para a análise das propriedades físicas coletaram-se amostras indeformadas com o uso de anéis volumétricos com dimensões médias de $0,04 \mathrm{~m}$ de altura e 0,05 $\mathrm{m}$ de diâmetro. Todas as variáveis físicas e químicas foram analisadas segundo Donagema et al. (2011). Vale ressaltar que o experimento foi delimitado com finalidades agronômicas, por isso, propôs avaliar a aplicação da ARS e sua influência nos teores de nutrientes e demais elementos químicos relacionados exclusivamente com o processo de absorção pelas plantas.

A modelagem matemática dos dados foi realizada com a utilização do software Minitab, versão 18 (Minitab, 2018). Inicialmente, foram retirados os outliers da variável resposta, a matéria orgânica do solo (MOS), trabalhou-se assim, com o conjunto de 117 dados amostrais. Nos GLMs, convencionou-se adotar a hierarquização das variáveis. As variáveis preditoras foram ainda classificadas em fatores (área, profundidade, tratamento, Ds e PT) e covariáveis (pH, $\mathrm{P}, \mathrm{Na}, \mathrm{S}, \mathrm{K}, \mathrm{Ca}, \mathrm{Mg}, \mathrm{Al}, \mathrm{Cu}, \mathrm{Fe}, \mathrm{Mn}$ e $\mathrm{Zn}$ ).

Para a organização dos aninhamentos, avaliaram-se as interações entre os fatores área, tratamento e profundidade, por possibilitarem interações em 30 níveis. Nesta condição, foram consideradas todas as combinações possíveis entre as três áreas experimentais (PS, LS e LD), os cinco tratamentos (T0, T1, T2, T3 e T4) e as duas profundidades (X e Y). Dessa forma, foram analisados os três aninhamentos triplos "Área*Tratamento*Profundidade", "Tratamento*Profundidade*Área" e "Profundidade*Área*Tratamento". Dentre os GLMs gerados selecionaram-se os que apresentaram ajuste satisfatório dos dados e possibilitaram boa interpretação da situação problema (McCullagh e Nelder, 2019). A metodologia de otimização de resposta foi empregada para complementar a análise dos GLMs e evidenciar o contexto de máxima expressão da MOS, considerando as variáveis ambientais.

\section{Resultados e discussão}

\section{Caracterização da ARS}

A Tabela 2 demonstra os valores de pH de 7,62, Demanda Bioquímica de Oxigênio (DBO) de 728,45 mg.L.- ${ }^{-1}$, Demanda Química da Oxigênio (DQO) de 1.956,45 mg.L ${ }^{-1}$ e Sólidos Suspensos Totais (SST) de 641,67 mg. $\mathrm{L}^{-1}$ da ARS tratada em biodigestor e utilizada no experimento. Tais parâmetros foram analisados de acordo com as metodologias ABNT NBR 9898:1999 (ABNT, 1999) para o pH, e SMWW 5210 B, SMWW 5220 D, SMWW 2540 D, para DBO, DQO e SST, respectivamente, segundo APHA (2012).

Machado et al. (2019) ao estudarem os parâmetros DBO, DQO e pH de ARS produzida em agroindústria familiar encontraram os valores $978,4 \pm 69,9$ mg. $\mathrm{L}^{-1}, 1.948,2 \pm$ 222,8 mg. $\mathrm{L}^{-1}$ e 6,8 $\pm 0,009 \mathrm{mg} . \mathrm{L}^{-1}$, respectivamente, valores semelhantes aos obtidos neste trabalho. Da mesma forma, Pereira et al. (2016) ao avaliarem a aplicação de diferentes dosagens de ARS com adição de adubos minerais em solo com plantio de milho verificaram que os valores de pH e DQO foram de 7,6 e 2.160 mg. $\mathrm{L}^{-1}$, respectivamente. Batista et al. (2014) também corroboram com os valores obtidos neste trabalho, ao revelarem que os valores de DBO foram de $602 \pm 252,43 \mathrm{mg} \cdot \mathrm{L}^{-1}$ e de $\mathrm{pH}$ de 7,54 $\pm 0,14$, na avaliação do desempenho hidráulico de sistemas de irrigação por gotejamento com ARS.

Entretanto, Souza et al. (2013) apresentam valores muito superiores para a DQO, ao avaliarem a produção de frutos de pimentão fertirrigado com ARS, fornecendo $100 \%$ e $200 \%$ da concentração de nitrogênio necessária à cultura obtiveram DQO de 9.996 mg.L ${ }^{-1}$. Por outro lado, também foram encontrados valores inferiores aos encontrados neste trabalho para DQO. Silva e Campos (2018), encontraram 233 mg. $\mathrm{L}^{-1}$ e 357,64 mg.L $\mathrm{L}^{-1}$, para DQO total e filtrada, respectivamente. Já Souza et al. (2010) encontraram 89 mg.L. $\mathrm{L}^{-1}$ e 370 mg. $\mathrm{L}^{-1}$, para DBO e DQO, respectivamente, ao aplicarem diferentes doses de ARS filtrada em solos com produção de tomates de mesa. 
Fia et al. (2017) também ratificam os resultados obtidos neste trabalho ao obter valores de $777 \pm 519 \mathrm{mg} . \mathrm{L}^{-1}, 2.492 \pm 1.705 \mathrm{mg} . \mathrm{L}^{-1}$ e $953 \pm 803 \mathrm{mg} . \mathrm{L}^{-1}$ para os parâmetros DBO, DQO e SST, respectivamente, quando compararam diferentes sistemas alagados construídos (SACs) para tratar a ARS na forma de DQO. Os pesquisadores afirmam ainda que após o tratamento a eficiência média de remoção foi estimada entre 83\%, 88\% e 79\%, bem como 82\%, 84\% e 90\%, respectivamente. Já Silva e Campos (2018) ao testarem o sistema de tratamento composto por um filtro anaeróbico de fluxo ascendente, obtiveram SST de 1112,5 mg. $\mathrm{L}^{-1}$, valor semelhante ao encontrado neste trabalho. No entanto, a eficiência para redução deste parâmetro foi de apenas 29,9\%. E os autores justificam a baixa eficiência devido à baixa taxa de remoção de matéria orgânica no sistema de tratamento.

Segundo Machado et al. (2019), os valores discrepantes de DBO e DQO entre os estudos analisados podem ser explicados pela variação de diversos fatores, dentre os quais citam-se os diferentes sistemas de tratamento da ARS, principalmente quanto ao tempo de retenção hidráulica (TRH), dieta dos animais e o uso de medicamentos. Já os valores de $\mathrm{pH}$ observados nos diferentes estudos enquadraram-se em faixa neutra, entre 6,0 e 8,0 .

Pereira et al. (2019) ao estudarem a digestão anaeróbica da ARS constataram que a taxa de biodegradabilidade alcançou $98 \% \pm 2 \%$. Sylvestre (2013), por sua vez, ao comparar sistemas de reatores anaeróbicos e aeróbicos na remoção de coliformes e ovos de helmintos de ARS constatou que as concentrações de ovos de helmintos nos efluentes foram inferiores a 1 ovo. $\mathrm{L}^{-1}$. No experimento, a eficiência dos reatores UASB (Upflow Anaerobic Sludge Blanket Reactor) em dois estágios alcançou 99,11\%, enquanto que no tratamento composto por UASB seguido de filtro anaeróbico, filtro biológico percolador e decantador a eficiência alcançou 100\%. Pinto et al. (2014) também determinaram eficiência de $100 \%$ quanto à redução de ovos de helmintos em reatores anaeróbicos em escala real e em lagoas de maturação para o tratamento de ARS, no afluente foram encontrados valores entre 2.891 a 88.848 ovos. $\mathrm{L}^{-1}$, enquanto que no efluente foi constatada a ausência de ovos.

Ambos os sistemas de tratamento propostos por Sylvestre (2013) revelaram elevado potencial de remoção de coliformes, atingindo valores de 99,51\% no sistema mais simples e 99,91\% no sistema mais complexo. Novaes e Lopes (2012) ao avaliarem o efluente tratado em biodigestor também encontraram valores significativos quanto à redução de Escherichia coli, cuja eficiência alcançou 99,99\%. Já Souza et al. (2013) constataram que a ARS tratada, produziu frutos de pimentão sem contaminação por coliformes termotolerantes e Salmonella spp.

Das análises microbiológicas descritas nas investigações supracitadas conclui-se que os dejetos de suínos submetidos à biodigestão anaeróbica apresentam redução significativa das concentrações de ovos de helmintos e coliformes totais e fecais. Ressaltase, portanto, que tais análises não foram realizadas neste trabalho devido à eficiência dos tratamentos anaeróbicos comprovada cientificamente. No entanto, apesar destes valores de eficiência, o efluente pode ainda não apresentar valores absolutos adequados para o seu lançamento em corpos d'água, principalmente, com relação aos demais nutrientes e elementos do solo (Brasil, 2011).

\section{Modelos Lineares Generalizados - GLMs}

As equações dos GLMs obtiveram o melhor ajuste $\left(R^{2}=96,38 \%\right)$ para o conjunto de 104 dados amostrais. A Tabela 4 demonstra que a constante das equações dos modelos e as variáveis Mg e Mn são significativas e, por possuírem coeficientes positivos, são diretamente proporcionais à dinâmica da variável resposta. 
Tabela 4. Coeficientes e significâncias gerados pelos GLMs para a matéria orgânica do solo (MOS), fixando os fatores profundidade, área e tratamento para as interações "Área*Tratamento*Profundidade", "Tratamento*Área*Profundidade"

"Profundidade*Tratamento*Área", respectivamente.

\begin{tabular}{|c|c|c|c|c|}
\hline \multirow{2}{*}{\multicolumn{2}{|c|}{ Termo }} & \multicolumn{2}{|c|}{ Matéria orgânica do solo (MOS) } & \multirow{2}{*}{ Significância } \\
\hline & & Coeficiente & p-value & \\
\hline \multicolumn{2}{|l|}{ Constante } & 1,310 & 0,000 & $* * *$ \\
\hline \multicolumn{2}{|l|}{$\mathrm{pH}$} & $-0,0520$ & 0,195 & ns \\
\hline \multicolumn{2}{|l|}{ Fósforo (P) } & 0,00434 & 0,152 & ns \\
\hline \multicolumn{2}{|l|}{ Sódio (Na) } & 0,000109 & 0,277 & ns \\
\hline \multicolumn{2}{|l|}{ Enxofre (S) } & $-0,00088$ & 0,471 & ns \\
\hline \multicolumn{2}{|l|}{ Potássio (K) } & $-0,000608$ & 0,270 & ns \\
\hline \multicolumn{2}{|l|}{ Cálcio (Ca) } & 0,0726 & 0,326 & ns \\
\hline \multicolumn{2}{|l|}{ Magnésio (Mg) } & 0,382 & 0,010 & ** \\
\hline \multicolumn{2}{|l|}{ Alumínio $(\mathrm{Al})$} & 0,0670 & 0,487 & ns \\
\hline \multicolumn{2}{|l|}{ Cobre $(\mathrm{Cu})$} & 0,0052 & 0,763 & ns \\
\hline \multicolumn{2}{|l|}{ Ferro (Fe) } & $-0,00083$ & 0,605 & ns \\
\hline \multicolumn{2}{|l|}{ Manganês (Mn) } & 0,01521 & 0,000 & $* * *$ \\
\hline \multicolumn{2}{|l|}{ Zinco (Zn) } & $-0,0007$ & 0,965 & ns \\
\hline \multirow{4}{*}{  } & $1,38-1,54$ & $-0,0163$ & 0,565 & ns \\
\hline & $1,54-1,60$ & $-0,0280$ & 0,311 & ns \\
\hline & $1,60-1,65$ & 0,0015 & 0,954 & ns \\
\hline & $1,65-1,77$ & 0,0429 & 0,131 & ns \\
\hline \multirow{4}{*}{$\begin{array}{c}\text { Fx. PT } \\
(\%)\end{array}$} & $34,85-39,90$ & $-0,0047$ & 0,867 & ns \\
\hline & $39,90-42,37$ & 0,0089 & 0,748 & ns \\
\hline & $42,37-43,97$ & $-0,0344$ & 0,194 & ns \\
\hline & $43,97-48,64$ & 0,0302 & 0,318 & ns \\
\hline
\end{tabular}

Fx. Ds: Faixa de densidade do solo; Fx. PT: Faixa de porosidade total do solo; **, ***, significância ao nível de 5\% e 1\%, respectivamente; ns: não significativo.

O aumento dos teores de Mn no solo também foi observado por Basso et al. (2012) em estudo na região oeste de Santa Catarina, principalmente na área onde o teor natural desse elemento no solo era menor e a aplicação de dejeto líquido de suínos ocorreu de maneira mais uniforme e controlada. Estes autores esclarecem ainda que a presença desse elemento no solo é devido à sua incorporação na ração dos animais na forma de complexos minerais. Entretanto, em Prior et al. (2015) não foram verificadas diferenças significativas entre as doses $\left(0,112,5,225,337,5\right.$ e $450 \mathrm{~m}^{3}$.ha- $\left.{ }^{-1}\right)$ de ARS, combinadas com adubações químicas, aplicadas em solo cultivado com milho.

$\mathrm{O} \mathrm{Mg}$, macronutriente do solo, também mostrou-se diretamente proporcional à MOS. Ros et al. (2017) ratifica este resultado ao avaliar o efeito das doses 0, 25, 50, 75 e $100 \mathrm{~m}^{3}$.ha' ${ }^{-1}$ de ARS e da adubação mineral nas culturas de girassol, canola, feijão e milho. Lourenzi et al. (2016) também constataram incremento de Mg após seis anos de aplicação de dejeto líquido de suínos com maravalha, em Latossolo Vermelho Distroférrico Típico, sob sistema de plantio direto. No entanto, no trabalho de Pessotto et al. (2018), o Mg não apresentou interações significativas entre as camadas de solo e os sistemas de manejo, que incluíam áreas de pastagem com uso excessivo de dejeto líquido de suínos, área de cultivo de grãos em plantio direto e área de mata nativa. 


\section{Aninhamento "Área*Tratamento*Profundidade"}

Com o fator Profundidade fixado notam-se que as camadas do solo apresentam a mesma significância e o mesmo módulo do coeficiente, por este motivo, as camadas X e Y possuem a mesma intensidade no GLM. São variáveis antagônicas porque enquanto a profundidade $\mathrm{X}$ contribui para aumento do teor de MOS; a profundidade Y favorece a sua redução (Tabela 5). Tal relação entre a profundidade do solo e o teor de MOS também foi verificada por Caovilla et al. (2010) e Pessotto et al. (2018).

Tabela 5. Coeficientes e significâncias gerados pelo GLM para a matéria orgânica do solo (MOS), fixando o fator profundidade, para a interação "Tratamento*Profundidade".

\begin{tabular}{|c|c|c|c|c|}
\hline \multirow{2}{*}{\multicolumn{2}{|c|}{ Fator }} & \multicolumn{2}{|c|}{ Matéria orgânica do solo (MOS) } & \multirow{3}{*}{$\begin{array}{c}\text { Significância } \\
\text { ns }\end{array}$} \\
\hline & & \multirow{2}{*}{$\begin{array}{c}\text { Coeficiente } \\
0,0135\end{array}$} & \multirow{2}{*}{$\begin{array}{c}\text { p-value } \\
0,398\end{array}$} & \\
\hline \multirow{2}{*}{ Profundidade } & $\mathrm{X}$ & & & \\
\hline & $\mathrm{Y}$ & $-0,0135$ & 0,398 & ns \\
\hline \multirow{10}{*}{ Tratamento*Profundidade } & T0*X & 0,0279 & 0,554 & ns \\
\hline & $\mathrm{T} 1 * \mathrm{X}$ & 0,0348 & 0,405 & ns \\
\hline & $\mathrm{T} 2 * \mathrm{X}$ & $-0,0454$ & 0,288 & ns \\
\hline & $\mathrm{T} 3 * \mathrm{X}$ & 0,0700 & 0,106 & ns \\
\hline & $\mathrm{T} 4 * \mathrm{X}$ & $-0,0873$ & 0,048 & $* *$ \\
\hline & $\mathrm{T} 0 * \mathrm{Y}$ & 0,0005 & 0,991 & ns \\
\hline & $\mathrm{T} 1 * \mathrm{Y}$ & $-0,0118$ & 0,786 & ns \\
\hline & $\mathrm{T} 2 * \mathrm{Y}$ & $-0,0002$ & 0,995 & ns \\
\hline & $\mathrm{T} 3 * \mathrm{Y}$ & 0,0520 & 0,249 & ns \\
\hline & $\mathrm{T} 4 * \mathrm{Y}$ & $-0,0405$ & 0,360 & ns \\
\hline
\end{tabular}

X: profundidade 0-0,2 m; Y: profundidade 0,2-0,4 m; T0: dose 0 de ARS; T1: dose $200 \mathrm{~m}^{3} \cdot \mathrm{ha}^{-1} \mathrm{de}^{-}$ ARS; T2: dose $400 \mathrm{~m}^{3} \cdot \mathrm{ha}^{-1}$ de ARS; T3: dose $600 \mathrm{~m}^{3}$.ha-1 de ARS; T4: dose $800 \mathrm{~m}^{3} \cdot \mathrm{ha}^{-1}$ de ARS; **: significância ao nível de 5\%; ns: não significativo.

A Tabela 5 demonstra ainda que na interação "Tratamento*Profundidade" apenas a associação "T4*X", cujo coeficiente é negativo, é significativa. Esta significância permite a compreensão de que a combinação entre a maior dosagem de ARS e a camada X contribui para a redução do teor de MOS. Malavolta et al. (2002) e Moura (2015) esclarecem que o aporte de materiais ricos em compostos orgânicos, como a ARS, proporciona aumento da quantidade de microrganismos e o consumo rápido dos nutrientes, o que reduz os teores de MOS, principalmente nas camadas mais profundas.

A Tabela 6, que demonstra o aninhamento "Área*Tratamento*Profundidade", evidencia que as combinações com a área LS, independente da dose de ARS aplicada e da profundidade, são diretamente proporcionais à dinâmica da variável de interesse.

Ao analisar as significâncias e os coeficientes das associações triplas, ressalta-se a interessante complementariedade de informações entre os aninhamentos duplos e triplos. Neste contexto, as informações obtidas nas interações entre dois fatores são consideradas na interação entre três fatores, o que permite inferências mais completas e complexas sobre a dinâmica da variável resposta.

Sob a perspectiva de complementariedade de informações, analisando a interação "T4*X", cujo coeficiente é negativo, em integração com a área PS, percebe-se que essa nova associação permanece com o coeficiente negativo, validando o resultado obtido da interação dupla. Por outro lado, o efeito sobre a variável resposta pode ser contrário. 
Nesta situação, ao considerar "T4*X" e sua combinação com a área LS, o coeficiente da interação tripla passa a ser positivo, indicando sua influência diretamente proporcional à MOS e, portanto, seu incremento (Tabela 6).

Tabela 6. Coeficientes e significâncias gerados pelo GLM para a matéria orgânica do solo (MOS), fixando o fator profundidade, para a interação "Área*Tratamento*Profundidade".

\begin{tabular}{|c|c|c|c|c|}
\hline \multirow{2}{*}{\multicolumn{2}{|c|}{ Fator }} & \multicolumn{3}{|c|}{ Matéria orgânica do solo (MOS) } \\
\hline & & \multirow{2}{*}{$\begin{array}{c}\text { Coeficiente } \\
-0,1409 \\
\end{array}$} & \multirow{2}{*}{$\frac{\text { p-value }}{0,053}$} & \multirow{2}{*}{$\begin{array}{c}\text { Significância } \\
* *\end{array}$} \\
\hline \multirow{30}{*}{ Área*Tratamento*Profundidade } & $\mathrm{LD}^{*} \mathrm{~T} 0 * \mathrm{X}$ & & & \\
\hline & $\mathrm{LS}^{*} \mathrm{~T} 0 * \mathrm{X}$ & 0,7217 & 0,000 & $* * *$ \\
\hline & PS*T0*X & $-0,5809$ & 0,000 & $* * *$ \\
\hline & LD*T1*X & $-0,3277$ & 0,000 & $* * *$ \\
\hline & $\mathrm{LS} * \mathrm{~T} 1 * \mathrm{X}$ & 0,6595 & 0,000 & $* * *$ \\
\hline & PS*T1*X & $-0,3318$ & 0,000 & $* * *$ \\
\hline & $\mathrm{LD} * \mathrm{~T} 2 * \mathrm{X}$ & 0,1022 & 0,164 & ns \\
\hline & $\mathrm{LS}^{*} \mathrm{~T} 2 * \mathrm{X}$ & 0,6116 & 0,000 & $* * *$ \\
\hline & PS*T2*X & $-0,7138$ & 0,000 & $* * *$ \\
\hline & LD*T3*X & $-0,0704$ & 0,345 & ns \\
\hline & LS*T3*X & 0,4604 & 0,000 & $* * *$ \\
\hline & PS*T3*X & $-0,3900$ & 0,000 & $* * *$ \\
\hline & $\mathrm{LD} * \mathrm{~T} 4 * \mathrm{X}$ & $-0,0979$ & 0,210 & ns \\
\hline & LS*T4*X & 0,6298 & 0,000 & $* * *$ \\
\hline & PS*T4*X & $-0,5318$ & 0,000 & $* * *$ \\
\hline & LD*T0*Y & $-0,1407$ & 0,038 & ** \\
\hline & $\mathrm{LS}^{*} \mathrm{~T} 0 * \mathrm{Y}$ & 0,5378 & 0,000 & $* * *$ \\
\hline & PS*T0*Y & $-0,3971$ & 0,000 & $* * *$ \\
\hline & LD*T1*Y & $-0,4598$ & 0,000 & $* * *$ \\
\hline & $\mathrm{LS}^{*} \mathrm{~T} 1 * \mathrm{Y}$ & 0,6939 & 0,000 & $* * *$ \\
\hline & PS*T1*Y & $-0,2342$ & 0,005 & $* *$ \\
\hline & $\mathrm{LD}^{* \mathrm{~T}} 2 * \mathrm{Y}$ & $-0,0867$ & 0,212 & ns \\
\hline & LS*T2*Y & 0,4646 & 0,000 & $* * *$ \\
\hline & $\mathrm{PS}^{*} \mathrm{~T} 2 * \mathrm{Y}$ & $-0,3778$ & 0,000 & *** \\
\hline & LD*T3*Y & $-0,2562$ & 0,001 & $* *$ \\
\hline & $\mathrm{LS}^{*} \mathrm{~T} 3 * \mathrm{Y}$ & 0,4541 & 0,000 & $* * *$ \\
\hline & PS*T3*Y & $-0,1978$ & 0,039 & $* *$ \\
\hline & $\mathrm{LD}^{* \mathrm{~T}} 4 * \mathrm{Y}$ & $-0,2515$ & 0,000 & $* * *$ \\
\hline & $\mathrm{LS}^{*} \mathrm{~T} 4 * \mathrm{Y}$ & 0,6037 & 0,000 & $* * *$ \\
\hline & $\mathrm{PS}^{*} \mathrm{~T} 4 * \mathrm{Y}$ & $-0,3522$ & 0,000 & $* * *$ \\
\hline
\end{tabular}

PS: Pastagem solteira; LS: SSP em linha simples; LD: SSP em linha dupla; T0: dose 0 de ARS; T1: dose $200 \mathrm{~m}^{3} \cdot$ ha $^{-1}$ de ARS; T2: dose $400 \mathrm{~m}^{3} \cdot \mathrm{ha}^{-1}$ de ARS; T3: dose $600 \mathrm{~m}^{3} \cdot$ ha $^{-1}$ de ARS; T4: dose $800 \mathrm{~m}^{3} \cdot \mathrm{ha}^{-1}$ de ARS; X: profundidade $0-0,2 \mathrm{~m}$; Y: profundidade $0,2-0,4 \mathrm{~m} ;{ }^{* *},{ }^{* * *}$, significância ao nível de $5 \%$ e $1 \%$, respectivamente; ns: não significativo.

\section{Aninhamento "Tratamento*Profundidade*Área"}

Com o fator Área fixado constata-se que apenas a área LS favorece o aumento do teor de MOS (Tabela 7). A equação deste modelo reforça o que foi comprovado no 
aninhamento "Área*Tratamento*Profundidade", que todas as associações estabelecidas com LS são diretamente proporcionais à dinâmica da variável de interesse (Tabela 6).

Tabela 7. Coeficientes e significâncias gerados pelo GLM para a matéria orgânica do solo (MOS), fixando o fator área, para a interação "Profundidade*Área".

\begin{tabular}{|l|c|c|c|c|}
\hline \multicolumn{2}{|c|}{ Fator } & \multicolumn{2}{|c|}{ Matéria orgânica do solo (MOS) } & \\
\cline { 3 - 5 } & LD & Coeficiente & p-value & Significância \\
\hline \multirow{3}{*}{ Área } & LS & $-0,1729$ & 0,000 & $* * *$ \\
\cline { 2 - 5 } & PS & 0,5837 & 0,000 & $* * *$ \\
\hline \multirow{3}{*}{ Profundidade*Área } & $\mathrm{X}^{*} \mathrm{LD}$ & $-0,4107$ & 0,000 & $* * *$ \\
\cline { 2 - 5 } & $\mathrm{Y}^{*} \mathrm{LD}$ & 0,0796 & 0,002 & $* *$ \\
\cline { 2 - 5 } & $\mathrm{X}^{*} \mathrm{LS}$ & $-0,0796$ & 0,002 & $*$ \\
\cline { 2 - 5 } & $\mathrm{Y}^{*} \mathrm{LS}$ & 0,0464 & 0,064 & $*$ \\
\cline { 2 - 5 } & $\mathrm{X}^{*} \mathrm{PS}$ & $-0,0464$ & 0,064 & $* *$ \\
\cline { 2 - 5 } & $\mathrm{Y}^{*} \mathrm{PS}$ & $-0,0854$ & 0,003 & $* *$ \\
\hline
\end{tabular}

PS: Pastagem solteira; LS: SSP em linha Simples; LD: SSP em linha dupla; X: profundidade 0-0,2 m; Y: profundidade $0,2-0,4 \mathrm{~m} ;{ }^{*},{ }^{* *},{ }^{* * *}$, significância ao nível de $10 \%, 5 \%$ e $1 \%$, respectivamente.

A Tabela 7 demonstra que todas as interações entre os fatores Profundidade e Área são significativas. No entanto, para as áreas de SSPs (LS e LD), a profundidade X destaca-se por configurar associações diretamente proporcionais a variável de interesse. Enquanto que na área PS percebe-se o contrário, ou seja, que a interação com a profundidade $\mathrm{X}$ favorece a redução do teor de MOS.

Na interação "Profundidade*Área", as associações "Y*LD", "Y*LS" e "Y*PS" são significativas, negativas e de mesma intensidade que as associações " $\mathrm{X}^{*} \mathrm{LD}$ ", " $\mathrm{X}$ * $L S^{\prime}$ e "X*PS", respectivamente, que por sua vez, são significativas e positivas. Tal resultado reforça a associação dos elevados teores de MOS com a profundidade X e a área LS, como também foi constatado fixando o fator Profundidade (Tabelas 5 e 6).

$\mathrm{Na}$ associação "Tratamento*Profundidade*Área" notam-se que as interações "T1*X*LD" e "T2* $X^{*} P S "$ são significativas e apresentam coeficientes negativos. Enquanto que as associações "T2* $\mathrm{X}^{*} \mathrm{LD}$ ", "T2*Y*LD", "T0*X*LS", "T1*X*PS", "T3*X*PS" e "T3*Y*PS" são significativas e positivas quanto a MOS (Tabela 8).

Destaca-se que a adição do fator Tratamento na interação pode, por um lado, alterar o comportamento da associação "Profundidade*Área", e por outro, confirmá-lo. A modificação do comportamento dos fatores pode ser comprovada ao analisar que a associação negativa "Y*LD", quando submetida ao tratamento T2 passa a se comportar de maneira positiva. 0 efeito contrário também ocorre e pode ser constatado no caso da interação " $\mathrm{X}^{*} \mathrm{LD}$ " com o tratamento T4, cujo coeficiente é negativo. Em contrapartida, a sua confirmação pode ser verificada quando a associação " $\mathrm{X} * \mathrm{LS}$ " permanece positiva quando submetida à T1, e "X*LD" à T2. Enquanto que a associação "Y*LD" permanece negativa sendo testada por T1, como mostra a Tabela 8. 
Tabela 8. Coeficientes e significâncias geradas pelo GLM para a matéria orgânica do solo (MOS), fixando o fator Área, para a interação "Tratamento*Profundidade*Área".

\begin{tabular}{|c|c|c|c|c|}
\hline \multirow{2}{*}{\multicolumn{2}{|c|}{ Fator }} & \multicolumn{2}{|c|}{ Matéria orgânica do solo (MOS) } & \multirow{3}{*}{$\begin{array}{c}\text { Significância } \\
\text { ns }\end{array}$} \\
\hline & & \multirow{2}{*}{$\begin{array}{c}\text { Coeficiente } \\
-0,0060\end{array}$} & \multirow{2}{*}{$\begin{array}{c}\text { p-value } \\
0,949\end{array}$} & \\
\hline \multirow{30}{*}{ Tratamento*Profundidade*Área } & $\mathrm{T} 0 * \mathrm{X}^{*} \mathrm{LD}$ & & & \\
\hline & $\mathrm{T} 1 * \mathrm{X}^{*} \mathrm{LD}$ & $-0,1859$ & 0,010 & ** \\
\hline & $\mathrm{T} 2 * \mathrm{X}^{*} \mathrm{LD}$ & 0,1637 & 0,013 & ** \\
\hline & T3*X*LD & 0,1065 & 0,151 & ns \\
\hline & $\mathrm{T} 4 * \mathrm{X}^{*} \mathrm{LD}$ & $-0,0783$ & 0,316 & ns \\
\hline & $\mathrm{T} 0 * \mathrm{Y}^{*} \mathrm{LD}$ & 0,0988 & 0,252 & ns \\
\hline & $\mathrm{T} 1 * \mathrm{Y}^{*} \mathrm{LD}$ & $-0,2326$ & 0,001 & $* *$ \\
\hline & $\mathrm{T} 2 * \mathrm{Y}^{*} \mathrm{LD}$ & 0,1520 & 0,022 & $* *$ \\
\hline & T3*Y*LD & 0,0348 & 0,634 & ns \\
\hline & $\mathrm{T} 4 * \mathrm{Y} * \mathrm{LD}$ & $-0,0530$ & 0,427 & ns \\
\hline & T0*X*LS & 0,1331 & 0,051 & $*$ \\
\hline & T1*X*LS & 0,0777 & 0,285 & ns \\
\hline & $\mathrm{T} 2 * \mathrm{X} * \mathrm{LS}$ & $-0,0504$ & 0,421 & ns \\
\hline & T3*X*LS & $-0,0862$ & 0,212 & ns \\
\hline & $\mathrm{T} 4 * \mathrm{X}^{*} \mathrm{LS}$ & $-0,0741$ & 0,282 & ns \\
\hline & T0*Y*LS & $-0,0125$ & 0,857 & ns \\
\hline & T1*Y*LS & 0,1313 & 0,117 & ns \\
\hline & T2*Y*LS & $-0,0865$ & 0,237 & ns \\
\hline & T3*Y*LS & $-0,0447$ & 0,514 & ns \\
\hline & T4*Y*LS & 0,0124 & 0,863 & ns \\
\hline & T0*X*PS & $-0,0433$ & 0,565 & ns \\
\hline & T1*X*PS & 0,2127 & 0,007 & $* *$ \\
\hline & T2*X*PS & $-0,2496$ & 0,009 & $* *$ \\
\hline & T3*X*PS & 0,1896 & 0,035 & $* *$ \\
\hline & T4*X*PS & $-0,1095$ & 0,101 & ns \\
\hline & T0*Y*PS & $-0,0847$ & 0,183 & ns \\
\hline & $\mathrm{T} 1 * \mathrm{Y}^{*} \mathrm{PS}$ & 0,0658 & 0,355 & ns \\
\hline & $\mathrm{T} 2 * \mathrm{Y}^{*} \mathrm{PS}$ & $-0,0662$ & 0,339 & ns \\
\hline & T3*Y*PS & 0,1660 & 0,051 & $*$ \\
\hline & $\mathrm{T} 4 * \mathrm{Y}^{*} \mathrm{PS}$ & $-0,0809$ & 0,264 & ns \\
\hline
\end{tabular}

T0: dose 0 de ARS; T1: dose $200 \mathrm{~m}^{3}$.ha-1 de ARS; T2: dose $400 \mathrm{~m}^{3}$.ha-1 de ARS; T3: dose $600 \mathrm{~m}^{3}$.ha-1 de ARS; T4: dose $800 \mathrm{~m}^{3} \cdot \mathrm{ha}^{-1}$ de ARS; X: profundidade 0-0,2 m; Y: profundidade 0,2-0,4 m; PS: Pastagem solteira; LS: SSP em linha Simples; LD: SSP em linha dupla; *, **, ***, significância ao nível de $10 \%, 5 \%$ e 1\%, respectivamente; ns: não significativo.

\section{Aninhamento "Profundidade*Área*Tratamento"}

A Tabela 9 aponta que apenas as doses $600 \mathrm{~m}^{3} \cdot$ ha $^{-1}$ e $800 \mathrm{~m}^{3} \cdot$ ha $^{-1}$ são significativas neste modelo. Enquanto T3 é diretamente proporcional ao comportamento da MOS, T4 contraria o efeito da variável resposta. É interessante ressaltar que o efeito dessas dosagens também foi verificado quando o fator Profundidade foi fixado (Tabelas 5 e 6). 
Tabela 9. Coeficientes e significâncias gerados pelo GLM para a matéria orgânica do solo (MOS), fixando o fator tratamento, para as interações Área*Tratamento e Profundidade*Área*Tratamento.

\begin{tabular}{|c|c|c|c|c|}
\hline \multirow{2}{*}{\multicolumn{2}{|c|}{ Fator }} & \multicolumn{2}{|c|}{ Matéria orgânica do solo (MOS) } & \multirow{3}{*}{$\begin{array}{c}\text { Significância } \\
\text { ns } \\
\end{array}$} \\
\hline & & \multirow{2}{*}{$\begin{array}{c}\text { Coeficiente } \\
0,0142 \\
\end{array}$} & \multirow{2}{*}{$\begin{array}{c}\text { p-value } \\
0,703\end{array}$} & \\
\hline \multirow{5}{*}{ Tratamento } & T0 & & & \\
\hline & $\mathrm{T} 1$ & 0,0115 & 0,699 & ns \\
\hline & $\mathrm{T} 2$ & $-0,0228$ & 0,443 & ns \\
\hline & T3 & 0,0610 & 0,066 & $*$ \\
\hline & $\mathrm{T} 4$ & $-0,0639$ & 0,061 & $*$ \\
\hline \multirow{15}{*}{ Área*Tratamento } & LD*T0 & $-0,1408$ & 0,016 & $* *$ \\
\hline & LS*T0 & 0,6297 & 0,000 & $* * *$ \\
\hline & PS*T0 & $-0,4890$ & 0,000 & $* * *$ \\
\hline & LD*T1 & $-0,3937$ & 0,000 & $* * *$ \\
\hline & LS*T1 & 0,6767 & 0,000 & $* * *$ \\
\hline & PS*T1 & $-0,2830$ & 0,000 & $* * *$ \\
\hline & LD*T2 & 0,0077 & 0,889 & ns \\
\hline & $\mathrm{LS}^{*} \mathrm{~T} 2$ & 0,5381 & 0,000 & $* * *$ \\
\hline & PS*T2 & $-0,5458$ & 0,000 & $* * *$ \\
\hline & LD*T3 & $-0,1633$ & 0,008 & $* *$ \\
\hline & LS*T3 & 0,4572 & 0,000 & $* * *$ \\
\hline & PS*T3 & $-0,2939$ & 0,000 & $* * *$ \\
\hline & LD*T4 & $-0,1747$ & 0,004 & $* *$ \\
\hline & LS*T4 & 0,6167 & 0,000 & $* * *$ \\
\hline & PS*T4 & $-0,4420$ & 0,000 & $* * *$ \\
\hline
\end{tabular}

T0: dose 0 de ARS; T1: dose $200 \mathrm{~m}^{3}$.ha-1 de ARS; T2: dose $400 \mathrm{~m}^{3}$.ha-1 de ARS; T3: dose $600 \mathrm{~m}^{3} \cdot \mathrm{ha}^{-1}$ de ARS; T4: dose $800 \mathrm{~m}^{3}$.ha-1 de ARS; PS: Pastagem solteira; LS: SSP em linha simples; LD: SSP em linha dupla; * **, ***, significância ao nível de $10 \%, 5 \%$ e 1\%, respectivamente; ns: não significativo.

A tendência de acréscimo da concentração de MOS em função da aplicação de ARS, como explicam Malavolta et al. (2002), não pode ser sustentada em todos os tratamentos deste experimento, uma vez que, a elevada carga orgânica aplicada em T4, intensifica a atividade microbiana no solo e o consumo rápido dos nutrientes, o que reduz, portanto, os teores de MOS (Moura, 2015).

Segundo Gama-Rodrigues e Gama-Rodrigues (1999) e Moura (2015), a ARS proporciona acréscimo da concentração de microrganismos no solo, uma vez que são adicionados compostos orgânicos. No entanto, o aumento da atividade microbiana com a ARS atinge seu limite quando se inicia a redução da sua atividade. Guerrero et al. (2007) verificaram que a atividade microbiana em áreas com aplicação de ARS, em poucos dias, tende a igualar-se às áreas sem aplicação do biofertilizante.

A Tabela 9 demonstra ainda que as associações significativas "LD*T0", "LD*T1", "LD*T3", "LD*T4", "PS*T0", "PS*T1", "LD*T1", "PS*T2", "PS*T3" e "PS*T4" são negativas enquanto que as associações "LS*T0", "LS*T1", "LS*T2", "LS*T3" e "LS*T4" são positivas. Neste sentido, as combinações com as áreas PS e LD, com exceção da interação "LD*T2", proporcionam teores reduzidos da MOS. Por outro lado, todas as associações com a área LS favorecem seu incremento, o que corrobora com o resultado apresentado na interação tripla "Área*Tratamento*Profundidade" (Tabela 6).

É interessante ressaltar que na interação entre os fatores Área e Tratamento observa-se que "LD*T1" e "LD*T3", cujos coeficientes são negativos, quando associados à profundidade $Y$, permanecem inversamente proporcionais à variável resposta. A mesma interpretação se estende as interações "PS*T2" e "PS*T4" e a profundidade X. 
Por outro lado, a interação "LS*T0" combinada com a profundidade X, permanece influenciando diretamente à dinâmica da variável resposta. No entanto, quando as associações "LD*T1" e "LD*T3" combinam-se com a profundidade X, o efeito sobre a MOS é contrário ao apresentado anteriormente. O mesmo acontece com "LS*T0", "PS*T2" e "PS*T4" em combinação com a profundidade Y.

No aninhamento "Profundidade*Área*Tratamento" as associações significativas "Y*LD*T1", "Y*LD*T2", "Y*LD*T3", "Y*LS*T0", "X*PS*T2" e "X*PS*T4" são negativas; enquanto que as associações "X*LD*T1", "X*LD*T2", "X*LS*T0", "X*LD*T3", "Y*PS*T2" e "Y*PS*T4" são positivas (Tabela 10).

Tabela 10. Coeficientes e significâncias gerados pelo GLM para a matéria orgânica do solo (MOS), fixando o fator tratamento, para a interação "Profundidade*Área*Tratamento".

\begin{tabular}{|c|c|c|c|c|}
\hline \multirow{2}{*}{\multicolumn{2}{|c|}{ Fator }} & \multicolumn{2}{|c|}{ Matéria orgânica do solo (MOS) } & \multirow{3}{*}{$\begin{array}{c}\text { Significância } \\
\text { ns } \\
\end{array}$} \\
\hline & & \multirow{2}{*}{$\begin{array}{c}\text { Coeficiente } \\
0,0271 \\
\end{array}$} & \multirow{2}{*}{$\begin{array}{c}\text { p-value } \\
0,589 \\
\end{array}$} & \\
\hline \multirow{30}{*}{ Profundidade*Área*Tratamento } & $\mathrm{X} * \mathrm{LD} * \mathrm{~T} 0$ & & & \\
\hline & Y*LD*T0 & $-0,0271$ & 0,589 & ns \\
\hline & $\mathrm{X}^{*} \mathrm{LS}^{*} \mathrm{~T} 0$ & 0,1192 & 0,017 & $* *$ \\
\hline & Y*LS*T0 & $-0,1192$ & 0,017 & $* *$ \\
\hline & X*PS*T0 & $-0,0647$ & 0,228 & ns \\
\hline & Y*PS*T0 & 0,0647 & 0,228 & ns \\
\hline & $\mathrm{X} * \mathrm{LD} * \mathrm{~T} 1$ & 0,1029 & 0,077 & $*$ \\
\hline & $\mathrm{Y}^{*} \mathrm{LD} \mathrm{N}^{*} 1$ & $-0,1029$ & 0,077 & $*$ \\
\hline & $\mathrm{X}^{*} \mathrm{LS} * \mathrm{~T} 1$ & 0,0196 & 0,754 & ns \\
\hline & $\mathrm{Y}^{*} \mathrm{LS} * \mathrm{~T} 1$ & $-0,0196$ & 0,754 & ns \\
\hline & X*PS*T1 & $-0,0120$ & 0,839 & ns \\
\hline & Y*PS*T1 & 0,0120 & 0,839 & ns \\
\hline & $\mathrm{X} * \mathrm{LD} * \mathrm{~T} 2$ & 0,0854 & 0,083 & $*$ \\
\hline & $\mathrm{Y}^{*} \mathrm{LD}^{*} \mathrm{~T} 2$ & $-0,0854$ & 0,083 & $*$ \\
\hline & $\mathrm{X}^{*} \mathrm{LS} * \mathrm{~T} 2$ & 0,0644 & 0,241 & ns \\
\hline & Y*LS*T2 & $-0,0644$ & 0,241 & ns \\
\hline & $\mathrm{X}^{*} \mathrm{PS} * \mathrm{~T} 2$ & $-0,1771$ & 0,009 & $* *$ \\
\hline & Y*PS*T2 & 0,1771 & 0,009 & $* *$ \\
\hline & $\mathrm{X} * \mathrm{LD} * \mathrm{~T} 3$ & 0,1154 & 0,019 & ** \\
\hline & $\mathrm{Y} * \mathrm{LD} * \mathrm{~T} 3$ & $-0,1154$ & 0,019 & ** \\
\hline & X*LS*T3 & 0,0257 & 0,603 & ns \\
\hline & Y*LS*T3 & $-0,0257$ & 0,603 & ns \\
\hline & X*PS*T3 & $-0,0736$ & 0,267 & ns \\
\hline & Y*PS*T3 & 0,0736 & 0,267 & ns \\
\hline & $\mathrm{X}^{*} \mathrm{LD}^{*} \mathrm{~T} 4$ & 0,0669 & 0,207 & ns \\
\hline & Y*LD*T4 & $-0,0669$ & 0,207 & ns \\
\hline & $\mathrm{X}^{*} \mathrm{LS}^{*} \mathrm{~T} 4$ & 0,0032 & 0,950 & ns \\
\hline & Y*LS*T4 & $-0,0032$ & 0,950 & ns \\
\hline & $\mathrm{X}^{*} \mathrm{PS} * \mathrm{~T} 4$ & $-0,0997$ & 0,060 & $*$ \\
\hline & Y*PS*T4 & 0,0997 & 0,060 & $*$ \\
\hline
\end{tabular}

T0: dose 0 de ARS; T1: dose $200 \mathrm{~m}^{3} \cdot \mathrm{ha}^{-1}$ de ARS; T2: dose $400 \mathrm{~m}^{3}$.ha-1 de ARS; T3: dose $600 \mathrm{~m}^{3} \cdot \mathrm{ha}^{-1}$ de ARS; T4: dose $800 \mathrm{~m}^{3}$.ha-1 de ARS; PS: Pastagem solteira; LS: SSP em linha simples; LD: SSP em linha dupla; X: profundidade 0-0,2 m; Y: profundidade $0,2-0,4 \mathrm{~m} ;{ }^{*}, * *, * *$, significância ao nível de $10 \%, 5 \%$ e $1 \%$, respectivamente; ns: não significativo. 
Ao analisar a interação "Profundidade*Área*Tratamento", notam-se que as significâncias e os módulos dos coeficientes são iguais para "X*LS*T0" e "Y*LS*T0", "X*LD*T1" e "Y*LD*T1", "X*LD*T2" e "Y*LD*T2", "X*LD*T3" e "Y*LD*T3", "X*PS*T3" e "Y*PS*T3", "X*PS*T4" e "Y*PS*T4". Essa condição permite afirmar que as profundidades X e Y possuem a mesma intensidade no modelo gerado, no entanto, são antagônicas. Neste contexto, as combinações com a profundidade $\mathrm{X}(0,0-0,2 \mathrm{~m})$ relacionam-se diretamente com a dinâmica da MOS, enquanto que o contrário é observado nas combinações com a profundidade $\mathrm{Y}(0,2-0,4 \mathrm{~m})$, o que valida os resultados apresentados nas Tabelas 5 e 7.

\section{Otimização de resposta}

Os modelos matemáticos de otimização de resposta quando aplicados em sistemas naturais ponderam as variáveis e suas interferências e evidenciam a conformação geral mais ajustada do estudo. Nesta pesquisa, a otimização de resposta foi utilizada para complementar a modelagem matemática da MOS proposta pelos GLMs com fatores aninhados.

Com o intuito de evidenciar a situação experimental cuja expressão da variável resposta seja máxima, optou-se pela maximização dos teores de MOS. Assim, permaneceram as covariáveis: $\mathrm{pH}, \mathrm{P}, \mathrm{K}, \mathrm{S}, \mathrm{Mg}, \mathrm{Ca}, \mathrm{Mn}, \mathrm{Cu}, \mathrm{Fe}, \mathrm{Zn}, \mathrm{Al}, \mathrm{Na}$; e os fatores: $\mathrm{Fx}$. Ds, Fx. PT, Área, Tratamento, Profundidade. As Tabelas 11 e 12 apresentam os valores ótimos das covariáveis e as condições ótimas dos fatores para a máxima expressão da MOS.

Tabela 11. Amplitude e valor ótimo das covariáveis para a otimização de resposta da MOS.

\begin{tabular}{|c|c|c|c|c|c|c|c|c|c|c|c|c|}
\hline \multirow{2}{*}{ Variável } & \multirow{2}{*}{ pH } & $\mathbf{P}$ & $\mathbf{K}$ & $\mathrm{Cu}$ & $\mathbf{F e}$ & Mn & $\mathbf{Z n}$ & $\mathrm{Na}$ & $\mathbf{S}$ & $\mathbf{C a}$ & Mg & Al \\
\hline & & \multicolumn{8}{|c|}{ - } & \multicolumn{3}{|c|}{-- $\operatorname{cmol}_{\mathbf{c}} \cdot \mathbf{d m}^{-3}$-- } \\
\hline V. Máx. & 6,0 & 30,9 & 264 & 8,2 & 86,0 & 30,5 & 7,7 & 640 & 45,0 & 3,1 & 0,9 & 1,05 \\
\hline V. Mín. & 2,1 & 0,5 & 7,0 & 0,4 & 4,0 & 0,6 & 0,2 & 10,0 & 2,0 & 0,1 & 0,1 & 0,0 \\
\hline V. Ótimo & 2,1 & 30,9 & 7,0 & 0,4 & 4,0 & 30,5 & 0,2 & 10,0 & 2,0 & 3,1 & 0,1 & 1,05 \\
\hline
\end{tabular}

V. Máx.: Valor máximo; V. Mín.: Valor mínimo; V. Ótimo: Valor ótimo.

Tabela 12. Configuração ótima dos fatores para a otimização de resposta da MOS.

\begin{tabular}{|l|c|c|}
\hline Variável & Níveis & Configuração Ótima \\
\hline Profundidade & $\mathrm{X} ; \mathrm{Y}$ & $\mathrm{X}$ \\
\hline Área & LD; LS; PS & LS \\
\hline Tratamento & T0; T1; T2; T3; T4 & T3 \\
\hline Fx. Ds & $1,28-1,54 ; 1,54-1,60 ; 1,60-1,64 ; 1,64-1,77$ & $1,28-1,54$ \\
\hline Fx. PT & $34,85-39,99 ; 39,99-42,31 ; 42,31-43,93 ; 43,93-49,36$ & $39,99-42,31$ \\
\hline
\end{tabular}

$\mathrm{X}$ : profundidade 0-0,2 m; Y: profundidade 0,2-0,4 m; PS: Pastagem solteira; LS: SSP em linha simples; LD: SSP em linha dupla; T0: dose 0 de ARS; T1: dose $200 \mathrm{~m}^{3}$.ha ${ }^{-1}$ de ARS; T2: dose $400 \mathrm{~m}^{3} \cdot \mathrm{ha}^{-1}$ de ARS); T3: dose $600 \mathrm{~m}^{3} \cdot \mathrm{ha}^{-1}$ de ARS); T4: dose $800 \mathrm{~m}^{3}$.ha $\mathrm{a}^{-1}$ de ARS; Fx. Ds: Faixa de densidade do solo $\left(\right.$ g. $\mathrm{cm}^{-3}$ ); Fx. PT: Faixa de porosidade total do solo (\%).

Verifica-se que a combinação dos teores mínimos de $\mathrm{pH}, \mathrm{K}, \mathrm{Cu}, \mathrm{Fe}, \mathrm{Zn}, \mathrm{Na}, \mathrm{S}$ e $\mathrm{Mg}$, dos teores máximos de $\mathrm{P}, \mathrm{Mn}, \mathrm{Ca}$ e Al, com as faixas 1,28-1,54 g.cm ${ }^{-3}$ de Ds e 39,99-42,31\% de PT, na profundidade $X$, com o tratamento T3, na área LS, elucidam a condição de máximo teor da $\operatorname{MOS}\left(3,48\right.$ dag. $\left.\mathrm{kg}^{-1}\right)$. 
A composição de conveniência (Desirability Composite - D) é utilizada para combinar diversos níveis de fatores, que quando agrupados, otimizam os resultados das variáveis respostas, e evidenciam o conjunto de condições ótimas para todas as respostas (Ma et al., 2014). Tendo em vista que a função D combina as funções Desirability individuais (d) de cada variável resposta do projeto e pondera seus resultados, assume-se que a importância atribuída à função d é máxima $(\mathrm{d}=1)$, uma vez que a variável resposta estipulada é única, a MOS.

As representações gráficas da otimização para as covariáveis e os fatores são apresentadas nas Figuras 1, 2 e 3. A linha contínua horizontal representa o valor previsto da maximização da MOS $\left(3,48\right.$ dag. $\left.\mathrm{kg}^{-1}\right)$. A linha contínua vertical representa o valor ótimo de cada variável na maximização da resposta. A linha tracejada representa a função $D$, na primeira linha de gráficos e o comportamento de cada covariável, na segunda linha de gráficos. Já as variáveis categóricas (fatores) são representadas por pontos (Figura 3).

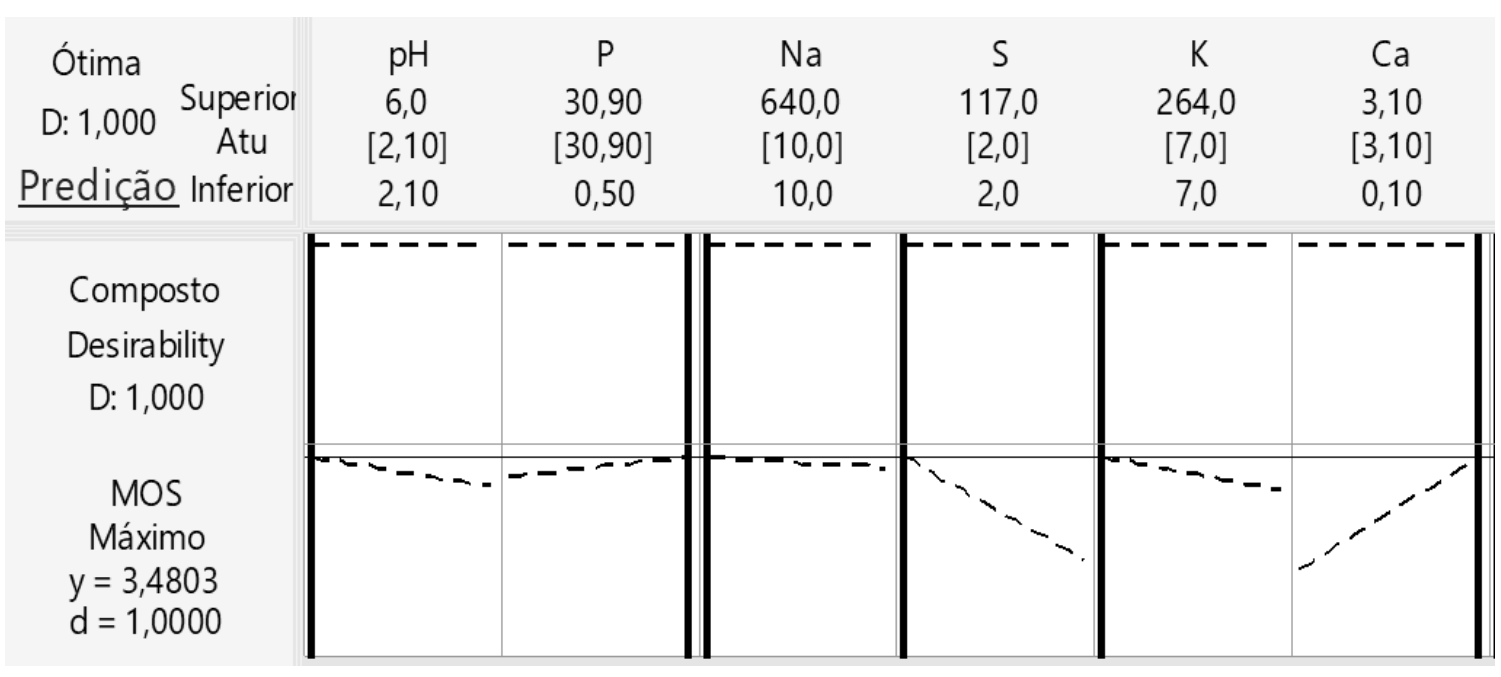

Figura 1. Otimização da matéria orgânica do solo (MOS) em função dos teores das covariáveis pH, $\mathrm{P}, \mathrm{Na}, \mathrm{S}, \mathrm{K}$ e Ca.

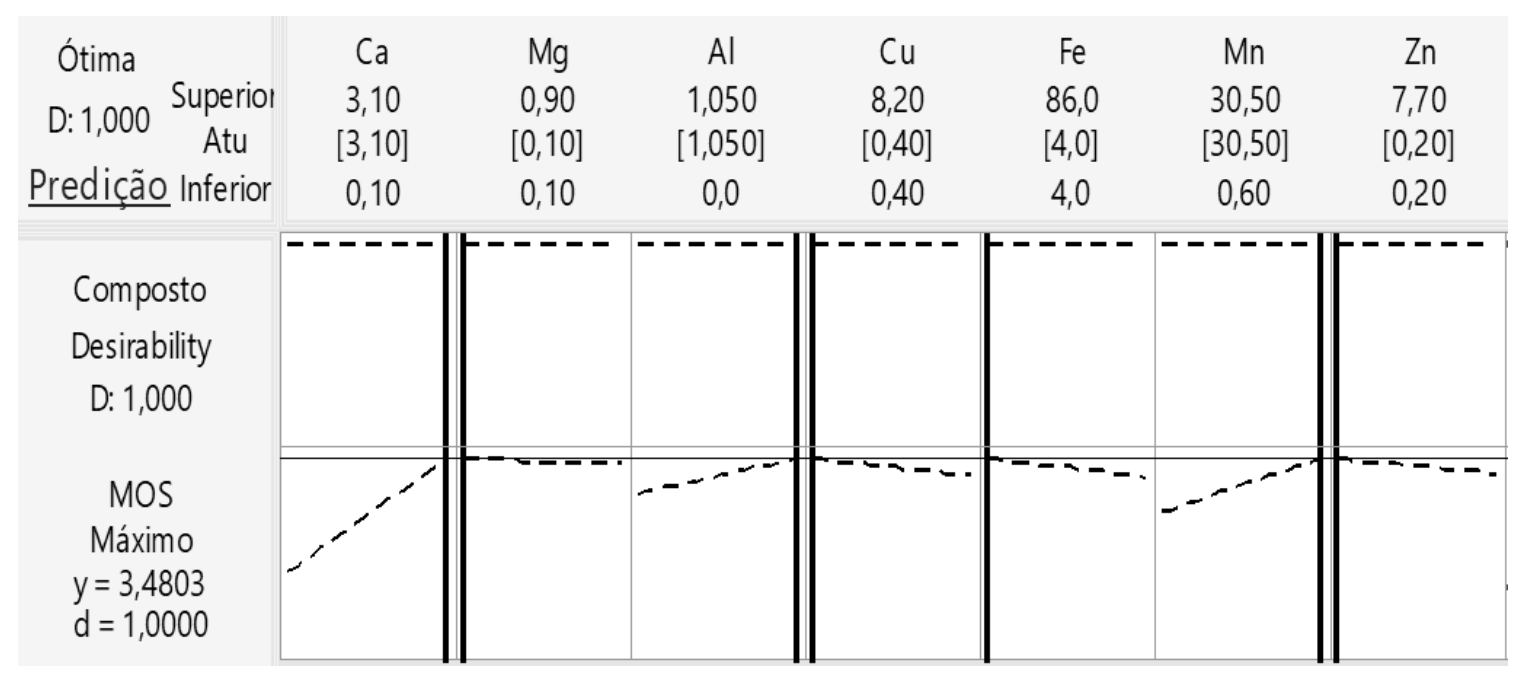

Figura 2. Otimização da matéria orgânica do solo (MOS) em função dos teores das covariáveis Mg, $\mathrm{Al}, \mathrm{Cu}, \mathrm{Fe}, \mathrm{Mn}$ e $\mathrm{Zn}$. 
As Figuras 1 e 2 mostram que conforme elevam-se os teores de $\mathrm{P}, \mathrm{Ca}, \mathrm{Al}$ e $\mathrm{Mn}$ constata-se incremento de MOS. Comparando-se a interferência diretamente proporcional destas variáveis percebe-se que os efeitos de $\mathrm{P}$ sobre a MOS são mínimos. Em contrapartida, o $\mathrm{pH}, \mathrm{Na}, \mathrm{S}, \mathrm{K}, \mathrm{Mg}, \mathrm{Cu}, \mathrm{Fe}$ e o $\mathrm{Zn}$ são as variáveis que se comportam de maneira contrária a variável resposta, isto é, conforme elevam-se seus teores, a concentração da MOS é reduzida. Os efeitos das variáveis $\mathrm{Mg}, \mathrm{Na}, \mathrm{Cu}, \mathrm{Fe}$, e $\mathrm{Zn}$ são mínimos quando comparados aos efeitos proporcionados por $\mathrm{S}, \mathrm{pH}$ e $\mathrm{K}$. De maneira geral, as variáveis que mais interferem para a maximização da variável resposta são os elementos $\mathrm{Ca}, \mathrm{Al}, \mathrm{Mn}, \mathrm{S}$ e $\mathrm{K}$, sendo os dois últimos, elementos que atuam contrariando $\mathrm{o}$ comportamento da MOS.

A Figura 3 mostra que os níveis ótimos dos fatores corroboram com a significância e com os coeficientes positivos gerados pelos GLMs. Além disso, ratificam o resultado obtido pelos aninhamentos triplos de que a profundidade $\mathrm{X}$ e a área LS são fatores determinantes para configurar teores elevados da MOS.

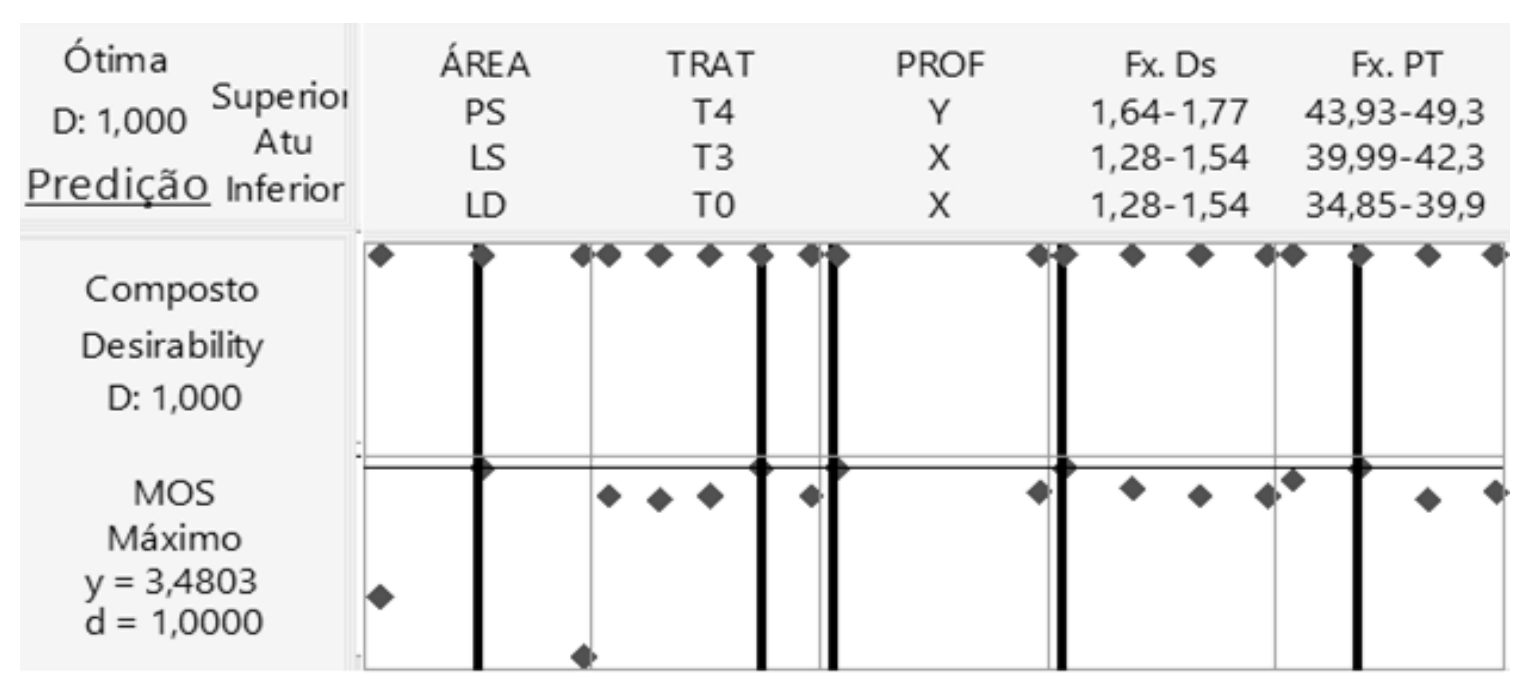

Figura 3. Otimização da Matéria Orgânica do Solo (MOS) em função dos níveis dos fatores Área, Tratamento, Profundidade, Fx. Ds e Fx. PT.

A análise dos atributos físicos, das características químicas do solo bem como dos tratamentos aplicados nas áreas experimentais permite a compreensão de que o maior valor verificado experimentalmente para o parâmetro $\operatorname{MOS}\left(2,40 \mathrm{dag} \cdot \mathrm{kg}^{-1}\right)$, quando submetido à metodologia de maximização da resposta, atinge 3,48 dag. $\mathrm{kg}^{-1}$. Apesar do interessante aumento do teor de MOS, sua classificação ainda permanece em nível médio, segundo a Comissão de Fertilidade do Solo do Estado de Minas Gerais (CFSEMG, 1999).

Lourenzi et al. (2016), Rhoden et al. (2017) e Pessotto et al. (2018) também observaram incrementos de MOS com aplicações de ARS, principalmente nas camadas mais superficiais do solo, o que valida o resultado obtido pela otimização de resposta. No entanto, Veiga et al. (2012) e Prior et al. (2015) não verificaram efeitos significativos neste parâmetro com sucessivas aplicações do biofertilizante em Latossolo Vermelho, sob sistema de plantio direto e em Latossolo Vermelho distroférrico típico cultivado com milho, respectivamente. 


\section{Conclusões}

O manganês $(\mathrm{Mn})$ e o magnésio $(\mathrm{Mg})$ destacam-se por serem as covariáveis cuja expressão é significativa e diretamente proporcional à dinâmica da matéria orgânica do solo (MOS) em todos os Modelos Lineares Generalizados (GLMs).

O cenário de máxima expressão da matéria orgânica do solo (MOS) é resultado da interação entre a área de sistema silvipastoril em linha simples (LS), submetido à dosagem de $600 \mathrm{~m}^{3} \cdot \mathrm{ha}^{-1}$ de água residuária da suinocultura (ARS), na profundidade 0,0-0,2 $\mathrm{m}(\mathrm{X}), \mathrm{o}$ que valida os resultados obtidos nos modelos matemáticos gerados.

\section{Conflito de interesses}

Os autores declaram não haver conflitos de interesses.

\section{Referências}

ABNT - Associação Brasileira de Normas Técnicas. ABNT NBR 9898:1999 - Preservação e técnicas de amostragem de efluentes líquidos e corpos receptores. Rio de Janeiro: ABNT, 1999.

ABPA - Associação Brasileira de Proteína Animal. Relatório anual 2020. São Paulo: ABPA, 2020. Disponível em: <http://abpa-br.org/wpcontent/uploads/2020/05/abpa_relatorio_ anual_2020_portugues_web.pdf>. Acesso em: 10 jul. 2020.

Alvares, C. A.; Stape, J. L.; Sentelhas, P. C.; Gonçalves, J. L. M.; Sparovek, G. Köppen's climate classification map for Brazil. Meteorologische Zeitschrift, v. 22, n. 6, p. 711-728, 2013. https://doi.org/10.1127/0941-2948/2013/0507

APHA - American Public Health Association. Standard methods for examination of water and wastewater. 22. ed. Washington: American Public Health Association, 2012.

Basso, C. J.; Ceretta, C. A.; Flores, É. M. M.; Girotto, E. Teores totais de metais pesados no solo após aplicação de dejeto líquido de suínos. Ciência Rural, v. 42, n. 4, p. 653-659, 2012. https://doi.org/10.1590/S0103-84782012000400012

Batista, R. O.; Oliveira, A. F. M.; Mesquita, F. O. Desempenho hidráulico de sistemas de irrigação por gotejamento operando com água residuária da suinocultura. Magistra, v. 26, n. 1, p. 75-88, 2014.

Brasil. Resolução CONAMA no 430, de 13 de maio de 2011. Dispõe sobre condições e padrões de lançamento de efluentes, complementa e altera a Resolução no 357, de 17 de março de 2005, do Conselho Nacional do Meio Ambiente-CONAMA. Disponível em: <http://www2.mma.gov.br/port/conama/legiabre.cfm?codlegi=646>. Acesso em: 10 jul. 2020.

Caovilla, F. A.; Sampaio, S. C.; Smanhotto, A.; Nóbrega, L. H.; Queiroz, M. M. Características químicas de solo cultivado com soja e irrigado com água residuária da suinocultura. Revista Brasileira de Engenharia Agrícola e Ambiental, v. 14, n. 7, p. 692-697, 2010. https://doi.org/10.1590/S1415-43662010000700002

CFSEMG - Comissão de Fertilidade do Solo do Estado de Minas Gerais. Recomendações para o uso de corretivos e fertilizantes em Minas Gerais. 4. ed. Lavras: CFSEMG, 1989. 
Cordeiro, G. M.; Demétrio, C. G. Modelos lineares generalizados e extensões. 2013. Disponível em: <https://docs.ufpr.br/ taconeli/CE22517/LivClarice.pdf>. Acesso em 10 jul. 2020.

Donagema, G. K.; Campos, D. B.; Calderano, S. B.; Teixeira, W. G.; Viana, J. M. Manual de métodos de análise de solos. 2. ed. rev. Rio de Janeiro: Embrapa Solos, 2011. (Documentos, 132).

Fia, F. R. L.; Matos, A. T.; Fia, R.; Borges, A. C.; Cecon, P. R. Efeito da vegetação em sistemas alagados construídos para tratar águas residuárias da suinocultura. Engenharia Sanitária

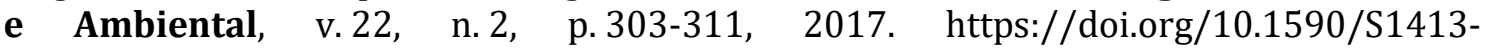
41522016123972

Gama-Rodrigues, E. F.; Gama-Rodrigues, A. C. Biomassa microbiana e ciclagem de nutrientes. In: Santos, G. A.; Silva, L. S.; Canellas, L. P.; Camargo, F. O. (Eds.). Fundamentos da matéria orgânica do solo ecossistemas tropicais \& subtropicais. 2. ed. Porto Alegre, Metrópole, 1999. p. 227-243.

Guerrero, C.; Moral, R.; Gómez, I.; Zornoza, R.; Arcenegui, V. Microbial biomass and activity of an agricultural aoil amended with the solid phase of pig slurries. Bioresource Technology, v. 98, n. 17, p. 3259-3264, 2007. https://doi.org/10.1016/j.biortech. 2006.07.015

Lourenzi, C. R.; Scherer, E. E.; Ceretta, C. A.; Tiecher, T. L.; Cancian, A.; Ferreira, P. A. A.; Brunetto, G. Atributos químicos de Latossolo após sucessivas aplicações de composto orgânico de dejeto líquido de suínos. Pesquisa Agropecuária Brasileira, v. 51, n. 3, p. 233-242, 2016. https://doi.org/10.1590/S0100-204X2016000300005

Ma, X. K.; Zhang, H.; Peterson, E. C.; Chen, L. Enhancing expolysacchariade antioxidante formation and yield from Phellinus species through medium optimization studies. Carbohydrate Polymers, v. 107, p. 214-220, 2014. https://doi.org/10.1016/j.carbpol. 2014.02.077

Machado, L.; Ferrarez, A. H.; Junio, J. L.; Oliveira, V. P. S.; Alves, F. C. Uso dos efluentes da suinocultura na fertirrigação: o caso de uma agroindústria familiar. Agropecuária Científica no Semiárido, v. 15. n. 1, p. 79-85, 2019. https://doi.org/10.30969/ acsa.v15i1.1112

Malavolta, E.; Pimentel G. F.; Alcarde, J. C. Adubos e adubações. São Paulo: Nobel, 2002.

McCullagh, P.; Nelder, J. A. Generalized linear models. Routledge: Chapman and Hall, 2019. (Monographs on Statistics and Apllied Probability, 37).

Minitab. Statistical Software. Versão 18.1. 2018. Disponível em: <http://www.minitab.com>. Acesso em: 20 nov. 2018.

Moura, A. C. Aspectos microbiológicos do sistema água residuária da suinoculturasolo. Cascavel: Universidade Estadual do Oeste do Paraná, 2015. (Tese de Doutorado).

Novaes, A. P.; Lopes, W. T. Avaliação físico-química de efluente gerado em biodigestor anaeróbio para fins de avaliação de eficiência e aplicação como fertilizante agrícola. Química Nova, v. 35, $\quad$ n. 1, p. 35-40, 2012. https://doi.org/10.1590/S010040422012000100007 
Pereira, E. L.; Morais, N. W. S.; Ferreira, T. J. T.; Leitão R. C.; Santos, A. B. Avaliação da biodegradabilidade anaeróbia e da produção de metano a partir da digestão anaeróbia da água residuária de suinocultura. Anais do 30 Congresso ABES 2019 - Congresso Brasileiro de Engenharia Sanitária e Ambiental, 2019.

Pereira, P. A.; Sampaio, S. C.; Reis, R. R. D.; Rosa, D. M.; Correa, M. M. Swine farm wastewater and mineral fertilization in corn cultivation. Revista Brasileira de Engenharia Agrícola e Ambiental, v. 20, n. 1, p. 49-54, 2016. https://doi.org/10.1590/ 1807-1929/agriambi.v20n1p49-54

Pessotto, P. P.; Silva, R. F.; Ros, C. O.; Silva, V. R.; Silva, D. A. A.; Grolli, A. L. Atributos químicos de um Neossolo Regolítico sob uso de dejeto de suínos. Revista de Ciências Agroveterinárias, $\quad$ v. 17, $\quad$ n. 3, $\quad$ p. 408-416, 2018. https://doi.org/10.5965/ 223811711732018408

Pinto, A. C. A.; Rodrigues, L. S.; Silva, I. J.; Zerbine, A. M.; Rodrigues, L. A. Emprego de reatores anaeróbios em escala real e lagoas de polimento para remoção de ovos de Ascaris suum de efluente de suinocultura. Semina: Ciências Agrárias, v. 35, n. 1, p. 343-349, 2014. https://doi.org/10.5433/1679-0359.2014v35n1p343

Prior, M.; Sampaio, S. C.; Nóbrega, L. H. P.; Dieter, J.; Costas, M. S. S. M. Estudo da associação de água residuária de suinocultura e adubação mineral na cultura do milho e no solo.

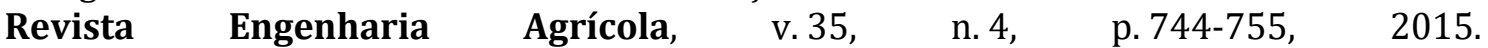
https://doi.org/10.1590/1809-4430-Eng.Agric.v35n4p744-755

Rhoden, A. C.; Klein, V.; Feldmann, N. A.; Muhl, F. R.; Balbinot, M.; Ritter, A. F. S. Parâmetros químicos do solo influenciados por aplicação de dejeto de suínos em áreas agrícolas do oeste catarinense. Revista de Ciências Agroveterinárias e Alimentos, n. 2, p. 1-12, 2017.

Ros, C. O.; Silva, V. R.; Silvestrin, T. B.; Silva, R. F.; Pessoto, P. P. Disponibilidade de nutrientes e acidez do solo após aplicações sucessivas de água residuária de suinocultura. Revista Brasileira de Tecnologia Agropecuária, v. 1, n. 1, p. 35-44, 2017.

Santos, H. G.; Jacomine, P. K. T.; Anjos, L. H. C.; Oliveira, J. B.; Coelho, M. R.; Lumbreras, J. F.; Cunha, T. J. F. Sistema brasileiro de classificação de solos. Brasília: Embrapa, 2013.

Silva, P. C.; Campos, C. M. M. Desempenho de um filtro anaeróbio de fluxo ascendente como unidade de tratamento para efluente de suinocultura. Ambiência, v. 14, n. 3, p. 561-578, 2018. http://doi.org/10.5935/ambiencia.2018.03.10

Smanhotto, A.; Sousa, A. D. P.; Sampaio, S. C.; Nóbrega, L. H.; Prior, M. Cobre e zinco no material percolado e no solo com a aplicação de água residuária de suinocultura em solo cultivado com soja. Engenharia Agrícola, v. 30, p. 347-357, 2010. https://doi.org/10.1590/S0100-69162010000200017

Souza, J. A. R.; Moreira, D. A.; Ferreira, P. A.; Matos, A. T. Avaliação de frutos de tomate de mesa produzidos com efluente do tratamento primário da água residuária da suinocultura. Revista Engenharia na Agricultura, v. 18, n. 3, p. 198-207, 2010.

Souza, J. A. R.; Moreira, D. A.; Martins, I. P.; Carvalho, C. V. M.; Carvalho, W. B. Sanidade de frutos de pimentão fertirrigados com água residuária da suinocultura. Ambi-Água, v. 8, n. 2, p 124-134, 2013. https://doi.org/10.4136/ambi-agua.1115

Sylvestre, S. H. Z. Desempenho de sistemas de reatores anaeróbios e aeróbio na remoção de coliformes e ovos de helmintos de águas residuárias de suinocultura. Jaboticabal: Universidade Estadual Paulista, 2013. (Dissertação de mestrado). 
Veiga, M.; Pandolfo, C. M.; Balbinot Junior, A. A.; Spangnollo, E. Chemical attributes of a Hapludox soil after nine years of a pig slurry application. Pesquisa Agropecuária Brasileira, v. 47, n. 12, p. 1766-1773, 2012. https://doi.org/10.1590/S0100204X2012001200013

Vilela, E. F.; Mendonça, E. S. Impacto de sistemas agroflorestais sobre a matéria orgânica do solo: modelagem de carbono e nitrogênio. Revista Coffee Science, v. 8, n. 3, p. 354-363, 2013.

Informação da Licença: Este é um artigo Open Access distribuído sob os termos da Licença Creative Commons Attribution, que permite uso irrestrito, distribuição e reprodução em qualquer meio, desde que a obra original seja devidamente citada. 